dr inz. Malgorzata Orczyk

dr inż. Bartosz Czechyra

Politechnika Poznańska

dr inz. Estera Wojciechowska

Instytut Pojazdów Szynowych ,Tabor”

\title{
Ocena poziomu halasu generowanego podczas faz ruchu wybranych typów tramwajów
}

\begin{abstract}
$W$ artykule przedstawiono wyniki pomiarów niestacjonarnych zdarzeń akustycznych wynikajacych z faz ruchu tramwaju. Analizie poddano zdarzenia akustyczne zwiazane z przyjazdem tramwaju na przystanek, otwarciem i zamknięciem drzwi, sygnałem dźwiękowym oraz odjazdem tramwaju z przystanku. Głównym celem artykułu jest próba oceny wpływu różnych typów tramwajów na ludzi znajdujacych się w obrębie przystanku? oczekujacych na przyjazd tramwaju oraz na klimat akustyczny miasta w porze wieczornej.
\end{abstract}

\section{Wprowadzenie}

Funkcjonowanie dużych ośrodków miejskich wiąże się nieodłącznie z ułatwianiem mieszkańcom przemieszczania się, niezależnie od powodów wywołujących zaistniałe potrzeby komunikacyjne oraz sposobów pokonywania przestrzeni. Zapewnienie sprawnie działającego systemu transportu publicznego w mieście jest zasadniczym problemem, od rozwiązania którego zależy prawidłowe funkcjonowanie każdego miasta.

Współcześnie coraz większą rolę w tworzeniu nowoczesnych miejskich systemów transportowych zarówno z powodów ekologicznych, jak i ekonomicznych odgrywają szynowe środki transportu. Komunikacja tramwajowa należy obecnie do najszybciej rozwijających się segmentów transportu publicznego w Polsce i w Unii Europejskiej. Wynika to przede wszystkim ze stosunkowo niskich kosztów inwestycyjnych budowy i modernizacji sieci tramwajowej, dostępności dla pasażera oraz wysokiej wydajności przewozowej przy stosunkowo niskich jednostkowych kosztach przypadających na pasażera. Zalety te wpłynęły między innymi na to, że komunikacja tramwajowa zaczyna powracać także do miast, które zlikwidowały tramwaje kilkadziesiąt lat temu [7].

\section{Kształtowanie klimatu akustycznego miasta}

Intensywny rozwój miast, przemysłu, sieci komunikacyjnych oraz lotnisk niesie ze sobą oprócz niewątpliwych korzyści gospodarczych, wiele negatywnych zjawisk. Jednym z nich jest zwiększanie emisji i zasiegu hałasu komunikacyjnego i przemysłowego na tereny zurbanizowane. Imisja hałasu na terenach osiedlowych i rekreacyjnych osiagnęła obecnie tak wysoki poziom, że przydatność ich do celów, do których zostały przeznaczone znacznie zmalała. Coraz częściej można spotkać tereny mieszkalne $\mathrm{w}$ ogóle nie przydatne do celów osiedlowych [11]. Badania monitoringu hałasu przeprowadzone przez organy Inspekcji Ochrony Środowiska wykazały, że liczba osób zagrożonych hałasem w Polsce zawiera się w granicach $13 \div 15 \mathrm{mln}$, a w porze dziennej średni równoważny poziom dźwięku w centrum miast wynosi około $L_{A}$ eq,dzien $\approx 72 \mathrm{~dB}[3,4]$.

Rozpatrując zagrożenie hałasem komunikacyjnym w mieście nie sposób pominąć ruchu tramwajowego. Wpływa na to fakt, że tramwaje eksploatowane są w centrach miast często o bardzo gęstej zabudowie, co sprawia, że ich uciążliwość dla mieszkańców może stawać się relatywnie duża szczególnie w porze wieczorno-nocnej. Badania wykonane w 1997 r. w ramach tzw. Państwowego Monitoringu Środowiska wykazały, że na oddziaływanie hałasu tramwajowego w Polsce było narażonych około 2,6 mln osób [3]. W chwili obecnej liczba osób narażonych na hałas tramwajowy w Polsce może okazać się większa, ze względu na fakt, że Polska zajmuje drugie miejsce w Unii Europejskiej pod względem długości sieci tramwajowej (14 systemów tramwajowych obejmujących 27 miast, łącznie 204 linie i $1445 \mathrm{~km}$ sieci) [7] W tabeli 1 zamieszczono przykładowe wyniki ekspozycyjnych poziomów dźwięku generowane przez tramwaje typu $105 \mathrm{~N}$ i $116 \mathrm{~N}$ podczas jazdy na różnych typach torowisk oraz podczas fazy hamowania.

\begin{tabular}{|c|c|c|c|}
\multicolumn{5}{|c|}{ Wyniki pomiarów ekspozycyjnych poziomów dźwięku } \\
dla taboru tramwajowego [4] \\
Tabela 1 \\
\begin{tabular}{|c|c|c|} 
Typ \\
tramwaju
\end{tabular} & $\begin{array}{c}\text { Torowisko } \\
\text { starego typu }\end{array}$ & $\begin{array}{c}\text { Torowisko } \\
\text { nowe }\end{array}$ & Hamowanie \\
\hline $105 \mathrm{~N}$ & 87,6 & 72,9 & 82,7 \\
\hline $116 \mathrm{~N}$ & 82,8 & 67,5 & 76,0 \\
\hline
\end{tabular}


Z danych zaprezentowanych w tabeli 1 wynika, że wartości ekspozycyjnego poziomu dźwięku generowanego przez wskazane tramwaje przekraczaja poziom $70 \mathrm{~dB}$. Na uzyskane tak wysokie poziomy dźwięku wpływa prędkość z jaką porusza się tramwaj jak również stan techniczny pojazdu oraz torowiska.

Autorzy w publikacji zajęli się zdarzeniami niestacjonarnymi wynikającymi z faz ruchu tramwaju, który dojeżdża do przystanku, otwiera i zamyka drzwi oraz odjeżdża z przystanku. Pomiarami objęto trzy typy tramwajów eksploatowanych przez MPK Wrocław:

$-105 \mathrm{Na}$,

- Škoda 16T,

- 205 WrAs.

Na podstawie uzyskanych wyników badań dokonano oceny narażenia akustycznego osób przebywających na przystanku tramwajowym i oczekujących na przyjazd tramwaju oraz przeanalizowano jak tramwaje wpływają na klimat akustyczny panujący w centrum miasta $\mathrm{W}$ porze wieczornej. Przedstawione wyniki pomiarów są wynikami badań wstępnych i będą stanowiły wprowadzenie do kolejnych bardziej szczegółowych badań i analiz.

\section{Uregulowania prawne związane $z$ monitorowa- niem hałasu tramwajowego w Polsce}

Wzrost zainteresowania w Polsce komunikacja tramwajową spowodował, że obecnie brakuje przepisów odnoszących się bezpośrednio do tramwajów. Podobna sytuacja występuje również w zakresie przepisów związanych $\mathrm{z}$ hałasem generowanym przez tramwaje w środowisku.

Unia Europejska w dyrektywie 2002/49/CE z dnia 25.06.2002 r w sprawie oceny i zarządzania poziomem hałasu w środowisku rekomenduje metody do prognozowania hałasu $\mathrm{w}$ środowisku związanymi $\mathrm{z}$ ruchem samochodowym, kolejowym i lotniczym, pomijając hałas tramwajowy. W rekomendowanej, holenderskiej metodzie prognozowania hałasu kolejowego, jedną z kategorii pociagów są metro i szybki tramwaj. Jednak ze względu na różnorodność konstrukcji torowisk i taboru tramwajowego eksploatowanego w Europie, bezpośrednie zastosowanie tej metody w Polsce nie jest możliwe.

Brak referencyjnego modelu prognozowania hałasu tramwajowego może oznaczać, że hałas ten nie stanowi poważnego zagrożenia $\mathrm{w}$ skali europejskiej. Inna sytuacja występuje w polskich miastach, gdzie hałas tramwajowy jest porównywany $\mathrm{z}$ hałasem samochodowym (zwłaszcza przy dużej prędkości tramwajów). Jest to konsekwencją złego stanu technicznego torowisk jak i taboru [1].

W zakresie diagnozowania poziomu hałasu tramwajowego w środowisku można wskazać dwa rozporządzenia Ministra Środowiska:
+ rozporządzenie w sprawie dopuszczalnych poziomów hałasu w środowisku [9]; które określa poziomy dopuszczalne uzależniając je od kategorii terenu objętego ochroną przed hałasem, rodzaju obiektu bądź działalności będącej źródłem hałasu,

+ rozporządzenie $\mathrm{w}$ sprawie wymagań w zakresie prowadzenia pomiarów poziomów $\mathrm{w}$ środowisku substancji lub energii przez zarządzającego drogą, linią kolejową linią tramwajową, lotniskiem, portem [10]; które ustala ogólne metodyki wykonywania pomiarów hałasu w środowisku związane z eksploatacją lądowych, wodnych i powietrznych środków transportu. Rozporządzenie to również nakłada obowiązek na zarządzających drogami, liniami kolejowymi, liniami tramwajowymi obowiązek okresowego monitorowania poziomu dźwięku.

W odniesieniu do hałasu samego pojazdu tramwajowego również brakuje jednoznacznych przepisów. Rozporządzenie Ministra Infrastruktury z dnia 22 grudnia $2003 \mathrm{r}$ w sprawie warunków technicznych tramwajów i trolejbusów oraz zakresu ich niezbędnego wyposażenia określa, że podczas jazdy tramwaju w odległości 7,5 m od osi toru na wysokości $1,6 \mathrm{~m}$ od główki szyny nie powinien być przekroczony poziom $88 \mathrm{~dB}(\mathrm{~A})$ przy założeniu, że pojazd porusza się z prędkością $50 \mathrm{~km} / \mathrm{h}$ po wydzielonym torowisku z podkładami żelbetowymi na tłuczniu. W przypadku postoju tramwaju przepis określa, że w odległości $3 \mathrm{~m}$ od dowolnej ściany wagonu, na wysokości $1,6 \mathrm{~m}$ od główki szyny poziom dźwięku nie powinien przekraczać $70 \mathrm{~dB}(\mathrm{~A})$ [8].

Bardzo często do pomiarów normatywnych hałasu tramwajowego zaleca się stosowanie norm kolejowych. W zakresie pomiarów hałasu zewnętrznego i wewnętrznego pojazdów szynowych wyróżnić można dwie normy $[5,6]$ :

- PN-EN ISO 3095:2005 Kolejnictwo - Akustyka pomiar hałasu emitowanego przez pojazdy szynowe.

- PN-EN ISO 3381:2005 Kolejnictwo - Akustyka pomiar hałasu wewnątrz pojazdów szynowych.

Obie z wymienionych norm określają tylko metodyki wykonania pomiaru hałasu zewnętrznego i wewnętrznego pojazdów szynowych jednak nie odnoszą się one bezpośrednio do tramwajów oraz nie zawierają wskazanych poziomów dźwięków, które byłyby uznane jako wartości dopuszczalne.

\section{Charakterystyka badanych tramwajów 4.1. Tramwaj typu Škoda 16T}

Tramwaje typu Škoda 16T są częściowo niskopodłogowymi (udział niskiej podłogi wynosi 65\%), pięcioczłonowymi i jednokierunkowymi tramwajami wyprodukowanymi w Pilznie przez czeskie zakłady Škoda Holding. Tramwaje te eksploatowane są od 2006 roku we Wrocławiu. 
Pudło tramwaju oparte jest na trzech wózkach. Wózki napędne wyposażone są $\mathrm{w}$ dwa trójfazowe asynchroniczne silniki o mocy $95 \mathrm{~kW}$ każdy. Pojazd wyposażono w trzy rodzaje hamulców: elektrohydrauliczny hamulec szczękowy, elektromagnetyczny hamulec szynowy oraz trakcyjny $z$ odzyskiem energii lub wytracaniem jej w rezystorach. Wymianę pasażerów zapewniają cztery pary podwójnych i dwie pary pojedynczych drzwi. Dodatkowo przy pierwszych drzwiach znajduje się wysuwana platforma umożliwiająca wjazd do tramwaju osobom niepełnosprawnym.

Tramwaj ten posiada 69 miejsc siedzacych i 174 miejsca stojące. Długość wagonu wynosi $31800 \mathrm{~mm}$, szerokość $2460 \mathrm{~mm}$, wysokość $3400 \mathrm{~mm}$, masa całkowita wagonu $37400 \mathrm{~kg}$ a maksymalna prędkość tramwaju wynosi około $70 \mathrm{~km} / \mathrm{h}$.

\subsection{Tramwaj typu 205 WrAs}

Sa to tramwaje produkowane od 2006 roku przez firmę RMT Protam Wrocław Sp.zo.o wzorowane na konstrukcji tramwaju $105 \mathrm{~N}$ i eksploatowane we Wrocławiu. Pojazd typu $205 \mathrm{WrAs}$ to przegubowy, trójczłonowy tramwaj z $22 \%$ udziałem niskiej podłogi, która została umieszczona w środkowej części wagonu (człon pierwszy i trzeci pojazdu nawiązuje do wagonów typu $204 \mathrm{WrAs}$ ). Wymiana pasażerów zapewniona jest przez pięć par podwójnych drzwi. Tramwaj wyposażony jest $\mathrm{w}$ osiem asynchronicznych silników o mocy $50 \mathrm{~kW}$ każdy. Pojazd posiada dwa rodzaje hamulców: hamulec bębnowy i elektromagnetyczny hamulec szynowy. Podczas hamowania istnieje możliwość rekuperacji energii elektrycznej do sieci.

Tramwaj typu $205 \mathrm{WrAs}$ jest przystosowany do przewozu około 135 osób, z czego 37 na miejscach siedzących. Długość wagonu wynosi $26550 \mathrm{~mm}$, szerokość $2355 \mathrm{~mm}$, wysokość $3300 \mathrm{~mm}$, masa całkowita wagonu wynosi $35000 \mathrm{~kg}$ a maksymalna prędkość z jaką może poruszać się wynosi około $80 \mathrm{~km} / \mathrm{h}$.

\subsection{Tramwaj typu $105 \mathrm{Na}$}

Tramwaje typu $105 \mathrm{Na}$ wyprodukowane przez chorzowskie zakłady Konstal i stanowią najpopularniejszy typ tramwajów eksploatowanych w Polsce. Konstrukcja tego tramwaju powstała w latach 70-tych, a ich produkcję zakończono w latach 90-tych. Pojazdy te wyposażone są w cztery silniki prądu stałego o mocy 41,5 kW każdy, połączone szeregowo z własnym wentylatorem. Hamowanie odbywa się elektrodynamicznie oraz za pomocą hamulców szczękowo-bębnowych $i$ hamulca szynowego.

Wagon posiada 20 miejsc siedzących i 105 stojących. Długość wagonu wynosi $13500 \mathrm{~mm}$, szerokość $2400 \mathrm{~mm}$, wysokość $3600 \mathrm{~mm}$, masa całkowita $16800 \mathrm{~kg}$, a maksymalna prędkość z jaką może poruszać się tramwaj wynosi około $70 \mathrm{~km} / \mathrm{h}[2,12,13,14]$.

\section{Metodyka pomiarów}

Badania polegały na rejestracji niestacjonarnych poziomów dźwięku, które wynikały z faz ruchu tramwaju przyjeżdżającego i odjeżdżającego z przystanku. Do badań wybrano trzy typy tramwajów: $105 \mathrm{Na}$, 205 WrAs i Škoda 16T.

Pomiary zrealizowane były na przystanku tramwajowym znajdującym się w centrum Wrocławia przy ulicy Oławskiej w dzień powszedni w porze wieczornej około godziny 21 . Wybór godzin wieczornych był podyktowany próbą oceny, jak dźwięki generowane przez przyjeżdżające i odjeżdżające $\mathrm{z}$ przystanku tramwaje mogą wpływać na klimat akustyczny miasta, oraz osób znajdujących się w otoczeniu przystanku.

$\mathrm{Na}$ podstawie przeprowadzonych badań wstępnych przyjęto poziom tha $L_{\text {Aeq, Tla }} \approx 58 \mathrm{~dB}$. Pomiary wykonano podczas normalnej pracy przewozowej tramwaju (razem z pasażerami). Punkt pomiarowy zlokalizowano w odległości w odległości $3 \mathrm{~m}$ od osi toru, na wysokości 1,6 m od główki szyny.

Wszystkie pomiary wykonano całkującym miernikiem poziomu dźwięku typu 2250 firmy Brüe$1 \&$ Kjær. W ramach pojedynczego pomiaru rejestrowano sygnał akustyczny oraz w czasie rzeczywistym wyznaczano następujące parametry sygnału akustycznego: maksymalny poziom dźwięku $L_{\text {Amax }}$, minimalny poziom dźwięku $L_{\text {Amin }}$, równoważny poziom dźwięku $L_{\text {Aeq }}$, oraz szczytowy poziom dźwięku $L_{\text {Cpeak }}$.

\section{Wyniki badań i wnioski}

Analizie poddano pięć sytuacji związanych z fazami ruchu tramwaju: przyjazd na przystanek, akustyczny sygnał dźwiękowy: wewnętrzny i zewnętrzny, zamknięcie drzwi i odjazd tramwaju z przystanku. W tabeli 2 przedstawiono uśrednione wyniki pomiarów uzyskane podczas przyjazdu tramwaju na przystanek.

Poziomy dźwięku zarejestrowane podczas przyjazdu tramwaju

Tabela 2

\begin{tabular}{|l|c|c|c|c|}
\hline Typ tramwaju & $\begin{array}{c}\boldsymbol{L}_{\text {Aeq }} \\
{[\mathbf{d B}]}\end{array}$ & $\begin{array}{c}\boldsymbol{L}_{\boldsymbol{C p e a k}_{\text {pea }}} \\
{[\mathbf{d B}]}\end{array}$ & $\begin{array}{c}\boldsymbol{L}_{\text {Amax }} \\
{[\mathbf{d B}]}\end{array}$ & $\begin{array}{c}\boldsymbol{L}_{\text {Amin }} \\
{[\mathbf{d B}]}\end{array}$ \\
\hline Škoda 16T & 75 & 96 & 78 & 76 \\
\hline $205 \mathrm{WrAs}$ & 71 & 93 & 72 & 69 \\
\hline $105 \mathrm{Na}$ & 74 & 95 & 75 & 72 \\
\hline
\end{tabular}

Przeprowadzone pomiary wykazały, że zmierzone równoważne poziomy dźwięku $L_{A e q}$, maksymalne poziomy dźwięku $L_{\text {Amax }}$ i minimalne poziomy dźwięku $L_{\text {Amin }}$ dla wszystkich analizowanych typów tramwajów podczas przyjazdu tramwajów na przystanek przekroczyły poziom $70 \mathrm{~dB}$. Poziomy równoważne zawierały się $\mathrm{W}$ przedziale $L_{\text {Aeq }}=71 \div 75 \mathrm{~dB}$, poziomy maksymalne mieściły się w zakresie $L_{A \max }=72 \div 78 \mathrm{~dB}$ 
a poziomy minimalne obejmowały wartości $L_{A-}$ ${ }_{\min }=69 \div 76 \mathrm{~dB}$. Najwyższą wartość równoważnego poziomu dźwięku zarejestrowano $\mathrm{w}$ tramwajach typu Škoda $16 \mathrm{~T}, L_{A e q}=75 \mathrm{~dB}$, a najniższą w tramwajach typu $205 \mathrm{WrAs} L_{A e q}=71 \mathrm{~dB}$. Biorąc pod uwagę poziomy szczytowe $L_{\text {Cpeak }}$ uzyskane wyniki badan zawierały się w przedziale $L_{\text {Cpeak }}=93 \div 96 \mathrm{~dB}$. Najwyższe poziomy szczytowe $L_{\text {Cpeak }}=96 \mathrm{~dB}$ uzyskały tramwaje typu Škoda 16T.

Tabele 3 i 4 obejmują wyniki pomiarów związane $\mathrm{z}$ akustycznymi sygnałami dźwiękowymi. Uzyskane wartości zarejestrowano w odległości $3 \mathrm{~m}$ od tramwaju.

Poziomy dźwięku zewnętrznej sygnalizacji akustycznej

Tabela 3

\begin{tabular}{|l|c|c|c|c|}
\hline Typ tramwaju & $\begin{array}{c}\boldsymbol{L}_{\text {Aeq }} \\
{[\mathbf{d B}]}\end{array}$ & $\begin{array}{c}\boldsymbol{L}_{\text {Cpeak }} \\
{[\mathbf{d B}]}\end{array}$ & $\begin{array}{c}\boldsymbol{L}_{\text {Amax }} \\
{[\mathbf{d B}]}\end{array}$ & $\begin{array}{c}\boldsymbol{L}_{\text {Amin }} \\
{[\mathbf{d B}]}\end{array}$ \\
\hline Škoda $16 \mathrm{~T}$ & 70 & 82 & 72 & 68 \\
\hline $205 \mathrm{WrAs}$ & 72 & 86 & 75 & 58 \\
\hline $105 \mathrm{Na}$ & 77 & 109 & 81 & 66 \\
\hline
\end{tabular}

Analizując uzyskane wyniki pomiarów dotyczące akustycznego zewnętrznego sygnału dźwiękowego stwierdzono, że najwyższe poziomy dźwięku uzyskały tramwaje typu $105 \mathrm{Na}$. Zmierzone równoważne poziomy dźwięku wynosiły $L_{A e q}=77 \mathrm{~dB}$ a szczytowe poziomy dźwięku przekroczyły poziom $L_{C p e-}$ $a_{a k}=100 \mathrm{~dB}$. Najcichszym wśród badanych typów tramwajów okazał się dzwonek w tramwajach typu Škoda 16T; zmierzone poziomy: równoważne, maksymalne i minimalne zawarte były $w$ zakresie $68 \div 72 \mathrm{~dB}$. Poziomy szczytowe wynosiły w tramwajach tego typu $L_{\text {Cpeak }}=82 \mathrm{~dB}$.

Poziomy dźwięku wewnętrznej sygnalizacji akustycznej

Tabela 4

\begin{tabular}{|l|c|c|c|c|}
\hline $\begin{array}{c}\text { Typ } \\
\text { tramwaju }\end{array}$ & $\boldsymbol{L}_{\text {Aeq }}[\mathbf{d B}]$ & $\begin{array}{c}\boldsymbol{L}_{\text {Cpeak }} \\
{[\mathbf{d B}]}\end{array}$ & $\begin{array}{c}\boldsymbol{L}_{\text {Amax }} \\
{[\mathbf{d B}]}\end{array}$ & $\begin{array}{c}\boldsymbol{L}_{\text {Amin }} \\
{[\mathbf{d B}]}\end{array}$ \\
\hline Škoda 16T & 60 & 83 & 62 & 58 \\
\hline $205 \mathrm{WrAs}$ & 65 & 85 & 67 & 61 \\
\hline $105 \mathrm{Na}$ & 63 & 85 & 66 & 59 \\
\hline
\end{tabular}

W przypadku wyników badań wykonanych dla sygnału dzwonka wewnętrznego (tabela 4) uzyskane wyniki pomiarów poziomu: równoważnego maksymalnego i minimalnego zawierały się $\mathrm{w}$ przedziale $58 \div 67 \mathrm{~dB}$. W przypadku poziomu równoważnego zanotowane poziomy dźwięku dla wszystkich typów badanych tramwajów nie przekroczyły poziomu $L_{A-}$ eq $=66 \mathrm{~dB}$. Najcichszymi wśród badanych typów tramwajów okazały się tramwaje typu Škoda 16T. Dla tego typu tramwajów średni równoważny poziom dźwięku wyniósł $L_{A e q}=60 \mathrm{~dB}$. Najgłośniejszy sygnał dzwonka zarejestrowano $\mathrm{w}$ tramwajach typu
205 WrAs. Średni równoważny poziom dźwięku wynosił w tych tramwajach $L_{A e q}=65 \mathrm{~dB}$. Poziomy szczytowe dla wszystkich typów badanych tramwajów nie przekroczyły $L_{\text {Cpeak }}=85 \mathrm{~dB}$.

Kolejna analizowana sytuacja odnosi się do zdarzeń akustycznych związanych z zamknięciem drzwi tramwaju. $\mathrm{W}$ tabeli 5 przedstawiono wyniki pomiarów hałasu podczas zamknięcia drzwi badanych tramwajów.

Poziomy dźwięku generowanego przez zamykanie drzwi

\begin{tabular}{|l|c|c|c|c|}
\hline \multicolumn{1}{|c|}{ Typ tramwaju } & $\begin{array}{c}\boldsymbol{L}_{\text {Aeq }} \\
{[\mathbf{d B}]}\end{array}$ & $\begin{array}{c}\boldsymbol{L}_{\text {Cpeak }} \\
{[\mathbf{d B}]}\end{array}$ & $\begin{array}{c}\boldsymbol{L}_{\text {Amax }} \\
{[\mathbf{d B}]}\end{array}$ & $\begin{array}{c}\boldsymbol{L}_{\text {Amin }} \\
{[\mathbf{d B}]}\end{array}$ \\
\hline Škoda 16T & 65 & 97 & 71 & 61 \\
\hline $205 \mathrm{WrAs}$ & 64 & 82 & 66 & 61 \\
\hline $105 \mathrm{Na}$ & 65 & 98 & 79 & 58 \\
\hline
\end{tabular}

W analizowanych przypadkach zarejestrowane równoważne, maksymalne i minimalne poziomy dźwięku zawierały się w przedziale $58 \div 71 \mathrm{~dB}$. Najwyższe poziomy równoważne zanotowano $\mathrm{w}$ tramwajach typu Škoda $16 \mathrm{~T}$ i $105 \mathrm{Na} L_{\text {Aeq }}=65 \mathrm{~dB}$. Poziomy maksymalne $\mathrm{w}$ obu analizowanych przypadkach nie przekroczyły $L_{A \max }=80 \mathrm{~dB}$, natomiast poziomy minimalne dźwięku nie przekroczyły $L_{A \min }=62 \mathrm{~dB}$. W tramwaju typu $205 \mathrm{WrAs}$ równoważny poziom dźwię$\mathrm{ku}$ wynosił $L_{\text {Aeq }}=64 \mathrm{~dB}$ natomiast poziomy maksymalne i minimalne nie przekroczyły $67 \mathrm{~dB}$. Najwyższe szczytowe poziomy dźwięku uzyskały tramwaje dwóch typów Škoda $16 \mathrm{~T} L_{\text {Cpeak }}=97 \mathrm{~dB}$ i $105 \mathrm{Na} L_{C p e-}$ ${ }_{a k}=98 \mathrm{~dB}$. W tramwajach typu $205 \mathrm{WrAs}$ szczytowy poziom dźwięku nie przekroczył $L_{\text {Cpeak }}=82 \mathrm{~dB}$.

Ostatnimi analizowanymi zdarzeniami akustycznymi były odjazdy tramwajów z przystanku. Wyniki pomiarów przedstawiono $\mathrm{w}$ tabeli 6 .

Poziomy dźwięku zarejestrowane podczas odjazdu tramwajów z przystanku

Tabela 6

\begin{tabular}{|l|c|c|c|c|}
\hline Typ tramwaju & $\begin{array}{c}\boldsymbol{L}_{\text {Aeq }} \\
{[\mathbf{d B}]}\end{array}$ & $\begin{array}{c}\boldsymbol{L}_{\text {Cpeak }} \\
{[\mathbf{d B}]}\end{array}$ & $\begin{array}{c}\boldsymbol{L}_{\text {Amax }} \\
{[\mathbf{d B}]}\end{array}$ & $\begin{array}{c}\boldsymbol{L}_{\text {Amin }} \\
{[\mathbf{d B}]}\end{array}$ \\
\hline Škoda $16 \mathrm{~T}$ & 76 & 98 & 78 & 75 \\
\hline $205 \mathrm{WrAs}$ & 75 & 97 & 77 & 74 \\
\hline $105 \mathrm{Na}$ & 74 & 95 & 74 & 73 \\
\hline
\end{tabular}

Dla badanych tramwajów zmierzone równoważne poziomy dźwięku zawierały się w przedziale $L_{A-}$ eq $=74 \div 76 \mathrm{~dB}$, maksymalne poziomy dźwięku $L_{A-}$ $\max =74 \div 78 \mathrm{~dB}$, minimalne poziomy dźwięku $L_{A-}$ $\min =73 \div 75 \mathrm{~dB}$. Najwyższe poziomy dźwięku uzyskały tramwaje typu Škoda 16T: poziom równoważny wynosił $L_{A e q}=76 \mathrm{~dB}$, poziom maksymalny $L_{A-}$ $\max =78 \mathrm{~dB}$, poziom minimalny $L_{\text {Amin }}=75 \mathrm{~dB}$, poziom szczytowy $L_{\text {Cpeak }}=98 \mathrm{~dB}$. Wśród badanych typów 
tramwajów podczas odjazdu z przystanku najcichszymi okazały się tramwaje typu $105 \mathrm{Na}$. Zarejestrowane poziomy równoważne, maksymalne i minimalne dźwięku dla tego tramwaju nie przekroczyły $75 \mathrm{~dB}$, natomiast zmierzony szczytowy poziom dźwięku wynosił $L_{\text {Cpeak }}=95 \mathrm{~dB}$.

\section{Podsumowanie}

W artykule przedstawiono wyniki pomiarów hałasu związanych $\mathrm{z}$ fazami jazdy trzech typów tramwajów 105Na, 205 WrAs i Škoda 16T. Pomiary wykonano w jednoznacznie powtarzalnych warunkach, co umożliwia obiektywne porównanie uzyskanych wyników. Otrzymane wyniki badań pozwalają na ogólną ocenę poziomu dźwięku wynikającego z poszczególnych faz jazdy wybranych typów tramwajów (przyjazdu i odjazdu z przystanku, wewnętrznych i zewnętrznych akustycznych sygnałów dźwiękowych oraz fazy zamykania drzwi). Na podstawie przeprowadzonych badań sformułowano następujące wnioski:

+ Najwyższe równoważne poziomy dźwięku $L_{A e q}$ przekraczające poziom $70 \mathrm{~dB}$ zarejestrowano dla faz związanych $\mathrm{z}$ przyjazdem, odjazdem tramwaju z przystanku oraz zewnętrznego akustycznego sygnału dźwiękowego. Zmierzone równoważne poziomy dźwięku osiągały dla tych przypadków poziom nawet $76 \mathrm{~dB}$.

+ Dla wewnętrznego akustycznego sygnału dźwiękowego i zamknięcia drzwi tramwaju we wszystkich objętymi pomiarami typach tramwajów zmierzone równoważne poziomy dźwięku nie przekroczyły poziomu $70 \mathrm{~dB}$.

+ Poziomy szczytowe $L_{\text {Cpeak }}$ zarejestrowane podczas pomiarów dla faz związanych z przyjazdem i odjazdem tramwaju z przystanku, zewnętrznego akustycznego sygnału dźwiękowego i zamknięciem drzwi tramwaju przekraczają we wszystkich typach badanych tramwajów poziom $90 \mathrm{~dB}$. Dla wewnętrznego akustycznego sygnału dźwiękowego uzyskane poziomy szczytowe $L_{C \text { - }}$ peak osiagają nawet poziom $86 \mathrm{~dB}$.

Analizując uzyskane wyniki pomiarów stwierdzono, że hałas generowany podczas badanych faz jazdy tramwajów może również znacząco wpływać na klimat akustyczny miasta. Rozporządzenie Ministra Środowiska w sprawie dopuszczalnych poziomów hałasu w środowisku z dnia 14 czerwca 2007 roku dla terenów w strefie śródmiejskiej miasta ustala poziom dopuszczalnych na poziomie $65 \mathrm{~dB}$ w ciągu dnia i $55 \mathrm{~dB}$ w ciagu nocy [9].

\section{Literatura}

[1] Kokowski P.: Mapa akustyczna hałasu tramwajowego. W: Materiaty Problem hałasu $w$ mieście. Hałas $w$ mieście - doświadczenia $i$ wyzwania, Poznań 16-17.10.2008, s. $163 \div 173$.

[2] Komunikacja Miejska Szczecin. Komunikat internetowy www.mkm.szczecin.pl, lipiec 2008.

[3] Kucharski R J.: Zagrożenie hałasem komunikacyj-

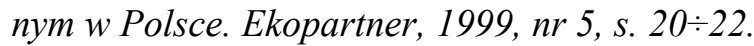

[4] Kucharski R J., Chyla A., KoszarnyZ., Kraszewski M., Szymański Z., Sakowska P., Taras A.: Stan klimatu akustycznego $w$ kraju $w$ świetle badań WIOŚ. Wyd. Biblioteki Monitoringu Środowiska, Warszawa 2002.

[5] Norma PN-EN ISO 3381:2005 KolejnictwoAkustyka-pomiar hałasu wewnatrz pojazdów szynowych.

[6] Norma PN-EN ISO 3095:2005 KolejnictwoAkustyka - pomiar hałasu emitowanego przez pojazdy szynowe.

[7] Raczyński J.: Miejski transport szynowy w Unii Europejskiej. Transport Miejski i Regionalny,

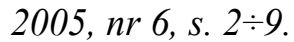

[8] Rozporzadzenie Ministra Infrastruktury z dnia 22 grudnia 2003 roku, w sprawie Warunków technicznych tramwajów i trolejbusów oraz zakresu ich niezbędnego wyposażenia. Dz. U nr 230, poz. 2300 i 2301.

[9] Rozporzadzenie Ministra Środowiska z dnia 14 czerwca 2007 roku, w sprawie Dopuszczalnych poziomów hałasu w środowisku. Dz. U. Nr 120, poz. 826.

[10] Rozporzqdzenie Ministra Środowiska z dnia 2 października 2007 roku, w sprawie Wymagań w zakresie prowadzenia pomiarów poziomów $w$ środowisku substancji lub energii przez zarzqdzajacego droga, linia kolejowa, liniq tramwajowa, lotniskiem, portem. Dz. U. nr 192, poz. 1392.

[11] Sadowski J.: Podstawy akustyki urbanistycznej. Wyd. Arkady, Warszawa, 1982.

[12] Tomaszewski F., OrczykM.: Ocena poziomu hałasu wewnętrznego tramwajów na podstawie

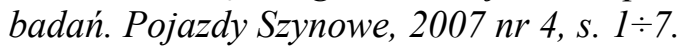

[13] Transport szynowy. Komunikat internetowy www.transportszynowy.pl, czerwiec 2008.

[14] Tramwaje w Polsce. Komunikat internetowy www.mlyniec.gda.pl, czerwiec 2008. 